\title{
Pseudohypercalcemia in a patient with multiple myeloma and acute kidney injury; a case report
}

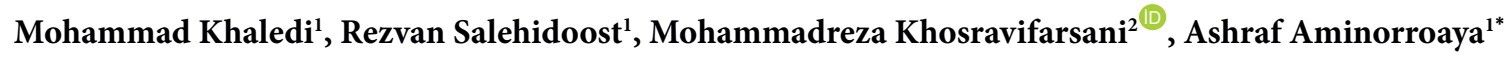 \\ ${ }^{1}$ Isfahan Endocrine and Metabolism Research Center, Isfahan University of Medical Sciences, Isfahan, Iran \\ ${ }^{2}$ Cancer Prevention Research Center, Isfahan University of medical sciences, Isfahan, Iran
}

\section{A R T I C L E I N F O}

\section{Article Type:}

Case Report

\section{Article History:}

Received: 13 October 2018

Accepted: 3 February 2019

ePublished: 18 February 2019

\section{Keywords:}

Pseudohypercalcemia

Multiple myeloma

Plasma cell neoplasm

Hypercalcemia

Glomerular filtration rate

Acute kidney injury

\begin{abstract}
A B S T RA C T
Here in this paper, we present a 60-year-old man admitted for generalized pain in his limbs and was finally diagnosed with multiple myeloma. He also underwent evaluation and treatments for his hypercalcemia $(15 \mathrm{mg} / \mathrm{dL})$. His calcium concentration did not respond well to different modalities and was along with a low parathyroid hormone (PTH) and elevated creatinine concentration $(12 \mathrm{mg} / \mathrm{dL})$. Further evaluations revealed normal ionized calcium which confirmed the diagnosis of pseudohypercalcemia. Multiple myeloma is a plasma cell neoplasm in which $10 \%$ of the patients suffer from true-hypercalcemia at the time of diagnosis. Pseudohypercalcemia is described as an elevated serum calcium concentration along with normal ionized calcium concentration and the absence of clinical symptoms of hypercalcemia. The cause of pseudohypercalcemia in multiple myeloma is due to the binding of calcium to increased abnormal immunoglobulins. The importance of this issue lies in the low PTH levels along with hypercalcemia and azotemia which is suggestive of pseudohypercalcemia.
\end{abstract}

Implication for health policy/practice/research/medical education:

Physicians must be careful and aware of pseudohypercalcemia in patients with multiple myeloma who have low PTH level despite renal failure. In such situations, ionized calcium concentration is suggested to be measured at the first step to prevent unnecessary treatments.

Please cite this paper as: Khaledi M, Salehidoost R Khosravifarsani M, Aminorroaya A. Pseudohypercalcemia in a patient with multiple myeloma and acute kidney injury; a case report. J Nephropharmacol. 2019;8(2):e15. DOI: 10.15171/npj.2019.15

\section{Introduction}

Calcium is one of the most important electrolytes that is necessary for different physiological processes. Hypercalcemia is a disorder associated with many clinical manifestations varying from asymptomatic to lifethreatening clinical situations while these manifestations are regardless of the background etiology (1). It should also be noted that symptoms of neurological dysfunction are often predominant in hypercalcemia. Etiologies of hypercalcemia are very different but primary hyperparathyroidism and malignancies are the most common etiologies. Pseudohypercalcemia is defined as elevated calcium concentration along with normal ionized calcium which might be due to binding of calcium to elevated serum proteins (2). Multiple myeloma is a plasma cell neoplasm and clinically significant hypercalcemia is reported in 1 of 3 multiple myeloma patients (3). The etiology of true hypercalcemia in multiple myeloma patients is due to diffuse bone break down and release of calcium but pseudohypercalcemia is very rare. Here we describe a 60-year-old man admitted and diagnosed with multiple myeloma which had asymptomatic elevated calcium concentration and was finally diagnosed with pseudohypercalcemia.

\section{Case Presentation}

A 60-year-old man was admitted to Al-Zahra hospital, Isfahan due to generalized pain in his limbs (mostly aggregated at nights), anorexia and weight loss (approximately $20 \mathrm{~kg}$ within the last three months). His limb pain lasted almost 3 hours at nights and did not respond to common analgesics such as nonsteroidal antiinflammatory drugs. The patient had a history of controlled diabetes mellitus from one year ago. Four months prior 
to his admission, he experienced multiple lumbar spinal compression fractures. He had no family history of hypercalcemia or any other endocrine or hematologic diseases. His drug history contained metformin $500 \mathrm{mg}$ twice daily. In his primary physical examinations, the patient had a body temperature of $37^{\circ} \mathrm{C}$ with a heart rate of 88 beats/min and blood pressure of 130/85 mm Hg. He had generalized bone pain however no tenderness was observed. He could not walk properly due to his former spinal fracture. All other physical examinations were normal. His initial laboratory data indicated serum calcium of $15 \mathrm{mg} / \mathrm{dL}$ with a normal albumin concentration $(4.6 \mathrm{~g} / \mathrm{dL})$ and anemia with a hemoglobin of $6.2 \mathrm{~g} / \mathrm{dL}$. He also had elevated serum creatinine $12 \mathrm{mg} / \mathrm{dL}$ which was suggestive of acute renal failure. Our patient had a low PTH concentration $(10.1 \mathrm{pg} / \mathrm{mL})$ and his urinary analysis indicated proteinuria $(3+)$ and glycosuria $(1+)$. All his initial laboratory data are summarized in Tables 1 , 2 and 3 . The clinical and laboratory data made our patient suspicion to multiple myeloma. His calcium concentration did not respond well to calcitonin. The patient scheduled for hemodialysis for his elevated calcium and creatinine. Serum calcium and creatinine decreased to $13 \mathrm{mg} / \mathrm{dL}$ and $4.3 \mathrm{mg} / \mathrm{dL}$ respectively then we became suspicious to pseudohypercalcemia according to no dramatic changes in serum calcium.

As the next step, serum and urinary protein electrophoresis and immunofixation were conducted for the diagnosis of multiple myeloma. Bence Jones protein was positive. Monoclonal gammopathy (IgA lambda) in serum (Figures 1 and 2) was detected. Bone marrow aspiration and biopsy showed diffuse plasma cell dyscrasia with diffuse infiltration of myeloma cells occupied more than $75 \%$ of marrow parenchyma (Figure 3). Therefore, the diagnosis of multiple myeloma was confirmed. Ionized calcium concentration was $1.31 \mathrm{mmol} / \mathrm{L}$ (normal

Table 1. Complete Blood Count of the patient with multiple myeloma and acute renal failure

\begin{tabular}{|c|c|}
\hline Test & Data \\
\hline $\mathrm{ESR}(\mathrm{mm})$ & 150 \\
\hline WBC $\left(/ \mathrm{mm}^{3}\right)$ & 4090 \\
\hline Neutrophils (\%) & 49.9 \\
\hline Lymphocytes (\%) & 40.1 \\
\hline Monocyte (\%) & 8.3 \\
\hline Platelet $\left(/ \mathrm{mm}^{3}\right)$ & 57000 \\
\hline $\mathrm{RBC}\left(\mathrm{Mil} / \mathrm{mm}^{3}\right)$ & 1.92 \\
\hline Hemoglobin (g/dL) & 6.2 \\
\hline Hematocrit (\%) & 19.6 \\
\hline $\operatorname{MCV}(f L)$ & 102.1 \\
\hline $\mathrm{MCH}(p g)$ & 32.3 \\
\hline $\mathrm{MCHC}(\mathrm{g} / \mathrm{dL})$ & 31.6 \\
\hline RDW CV (\%) & 13.7 \\
\hline
\end{tabular}

ESR: Erythrocyte sedimentation rate, WBC: White Blood Cell, RBC: Red Blood Cell, MCV: Mean corpuscular volume, $\mathrm{MCH}$ : Mean corpuscular hemoglobin concentration, RDW: Red Cell Distribution Width.
Table 2. Blood chemistry and hormones of the patient with multiple myeloma and acute renal failure

\begin{tabular}{lc}
\hline Test & Data \\
\hline Albumin (g/dL) & 4.6 \\
ALP (IU/l) & 507 \\
Urea (mg/dL) & 207 \\
Creatinine (mg/dL) & 12 \\
Calcium (mg/dL) & 15 \\
Phosphorus (mg/dL) & 7 \\
PTH (pg/ml) & 10.1 \\
FBS (mg/dL) & 106 \\
Glucose (2 h postprandial) (mg/dL) & 112 \\
HbA1C (\%) & 6 \\
Na (meq/L) & 135 \\
K (meq/L) & 5 \\
LDH (U/L) & 273 \\
\hline
\end{tabular}

ALP: Alkaline phosphatase, PTH: Parathyroid hormone, FBS: Fasting Blood Sugar, HbA1C: Hemoglobin A1C, LDH: Lactate Dehydrogenase.

Table 3. Urinalysis of the patient with multiple myeloma and acute renal failure

\begin{tabular}{|c|c|}
\hline Test & Data \\
\hline Color & Yellow \\
\hline Appearance & Clear \\
\hline Specific gravity & 1029 \\
\hline $\mathrm{pH}$ & 6 \\
\hline Protein & $(3+)$ \\
\hline Glucose & $(1+)$ \\
\hline Ketone & $(-)$ \\
\hline Amino acid & $(-)$ \\
\hline Blood & $(-)$ \\
\hline Bilirubin & $(-)$ \\
\hline Urobilirubin & $(-)$ \\
\hline Nitrogen & $(-)$ \\
\hline $\mathrm{RBC}$ & $1-2$ \\
\hline WBC & $2-4$ \\
\hline Epithelial cell & $0-1$ \\
\hline Bacteria & $(-)$ \\
\hline Crystal & $(-)$ \\
\hline Cast & $(-)$ \\
\hline Mucus & $(-)$ \\
\hline Yeast & $(-)$ \\
\hline
\end{tabular}

$(+)$ : Present, (-): Absent, RBC: Red Blood Cell, WBC: White Blood Cell.

range; 1.12 to $1.32 \mathrm{mmol} / \mathrm{L})$. Accordingly we diagnosed pseudohypercalcemia by a normal ionized calcium concentration along with elevated total calcium in the serum. Afterwards, the patient underwent anti-myeloma treatments (bortezomib, thalidomide, and dexamethasone) and no further treatments were performed for his calcium concentration. The patient was then discharged within 12 days after anti-myeloma treatments with the total calcium concentration of $9.8 \mathrm{mg} / \mathrm{dL}$. Laboratory data at the time of discharge are summarized in Table 4 . Follow up serum calcium after 4 weeks was also $9 \mathrm{mg} / \mathrm{dL}$. 


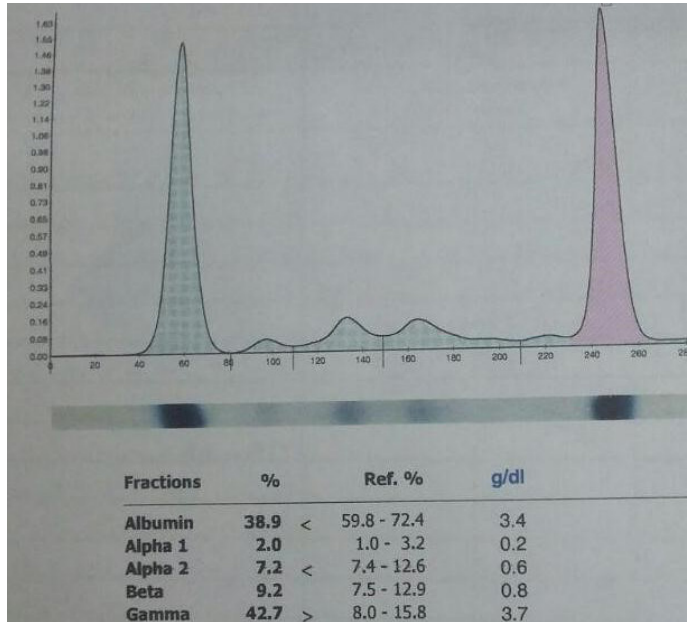

Figure 1. Serum protein electrophoresis indicating hypergammaglobulinemia.

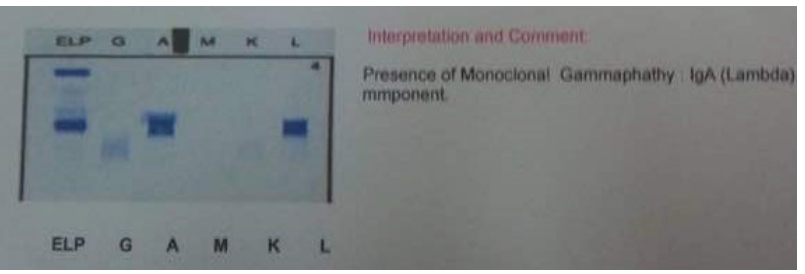

Figure 2. Serum immune fixation indicating monoclonal gammopathy ( $\lg$ A Lambda).

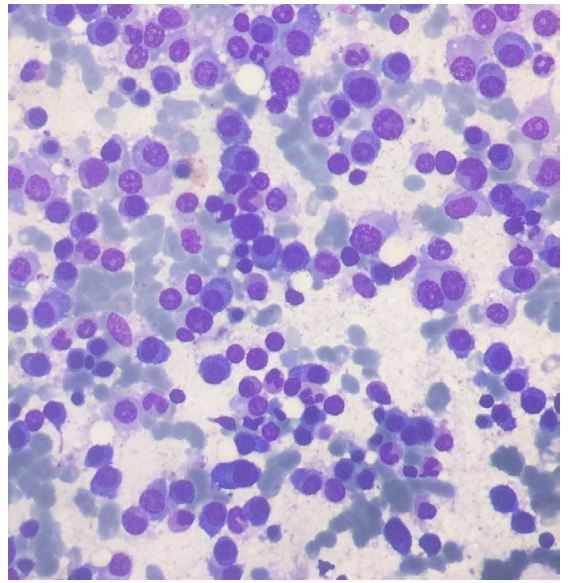

Figure 3. Bone marrow aspirations showing diffused plasma cell dyscrasia and diffuse infiltration of myeloma cells.

\section{Discussion}

Pseudohypercalcemia is a rare phenomenon, defined as elevated serum calcium concentration with normal ionized calcium. Ionized calcium concentration should be measured when severe hypercalcemia with absence of clinical symptoms presents. This state can occur under different conditions such as paraproteinemia or elevated concentration of proteins in serum,
Table 4. Laboratory data at the time of discharging of the patient with multiple myeloma and acute renal failure

\begin{tabular}{lc}
\hline Test & Data \\
\hline Albumin (g/dL) & 3.8 \\
BUN (mg/dL) & 76 \\
Creatinine (mg/dL) & 6.5 \\
Calcium (mg/dL) & 9.8 \\
Phosphorus (mg/dL) & 5.7 \\
Hemoglobin (g/dL) & 7.8 \\
FBS (mg/dL) & 98 \\
Na (meq/L) & 133 \\
K (meq/L) & 4.5 \\
\hline
\end{tabular}

BUN: blood urea nitrogen, FBS: fasting blood sugar.

hypergammaglobulinemia, dehydration and excessive serum albumin (4). In this state, calcium binds to proteins in serum but ionized calcium concentration remains normal without no signs and symptoms of hypercalcemia (2). As Shane and colleagues reported (1), true hypercalcemia is a condition in which serum calcium concentration and ionized calcium are elevated while symptoms of hypercalcemia are present. Symptoms of hypercalcemia including, gastrointestinal symptoms, loss of consciousness, polydipsia, polyuria and dehydration. True hypercalcemia can be caused by many reasons but is a common complication of multiple myeloma(3). As we described earlier, our patient had none of such symptoms however, he had an elevated calcium concentration. There had been similar cases with pseudohypercalcemia in patients with multiple myeloma (5-7). As Cicci et al described (8), hypercalcemia can complicate the management of myeloma by precipitating dehydration and prerenal azotemia as our patient had azotemia. It has been also reported that a standard approach to hypercalcemia following a malignancy is fluid resuscitation (9). However as we described, administration of intravenous fluid therapy was contraindicated due to decreased glomerular filtration rate.

\section{Conclusion}

Taken together, physicians must be careful and aware of pseudohypercalcemia in patients with multiple myeloma who have low PTH level despite renal failure. In such situations, ionized calcium concentration is suggested to be measured at the first step to prevent unnecessary treatments.

\section{Authors' contribution}

MKha; Data acquisition, literature review and drafting of the manuscript. MKho; drafting of the manuscript and final approval of the article. RS and AA; data acquisition, literature review, and drafting of the manuscript. All authors read and signed the final paper. 


\section{Conflicts of interest}

The authors report no conflicts of interest.

\section{Ethical considerations}

Ethical issues (including plagiarism, data fabrication, double publication) have been completely observed by the authors. The patient has given his informed consent regarding the publication of this case report.

\section{Funding/Support}

None.

\section{References}

1. Shane E, Dinaz I. Hypercalcemia: pathogenesis, clinical manifestations, differential diagnosis, and management. In: Favus MJ, ed. Primer on the Metabolic Bone Diseases and Disorders of Mineral Metabolism. Philadelphia: Lippincott, Williams \&Wilkins; 1999:183-87.

2. Wysolmerski JJ. Miscellaneous causes of hypercalcemia. Primer on the metabolic bone diseases and disorders of mineral metabolism. 6th ed. Washington, DC: American
Society for Bone and Mineral Research; 2006;6:203-8.

3. Oyajobi BO. Multiple myeloma/hypercalcemia. Arthritis research \& therapy. 2007; 9:S4. doi: 10.1186/ar2168

4. Ashrafi F, Iraj B, Nematollahi P, Darakhshandeh A. Pseudohypercalcemia in Multiple Myeloma: A Case Report. Int J Hematol Oncol Stem Cell Res. 2017; 11:246-9.

5. Schwab JD, Strack MA, Hughes LD, Shaker JL. Pseudohypercalcemia in an elderly patient with multiple myeloma: report of a case and review of literature. Endocr Pract. 1995;1(6):390-2. doi: 10.4158/EP.1.6.390.

6. Annesley TM,Burritt MF,Kyle RA. Artifactual hypercalcemia in multiple myeloma. Mayo Clin Proc. 1982; 57:572-5.

7. Jaffe JP,Mosher DF. Calcium binding by a myeloma protein. Am J Med. 1979; 67:343-6.

8. Cicci JD, Buie L, Bates J, van Deventer H. Denosumab for the management of hypercalcemia of malignancy in patients with multiple myeloma and renal dysfunction. Clin Lymphoma Myeloma Leuk. 2014; 14:e207-11. doi: 10.1016/j.clml.2014.07.005.

9. Basso U, Maruzzo M, Roma A, Camozzi V, Luisetto G, Lumachi F. Malignant hypercalcemia. Curr Med Chem. 2011;18:3462-7.

Copyright $\odot 2019$ The Author(s); Published by Society of Diabetic Nephropathy Prevention. This is an open-access article distributed under the terms of the Creative Commons Attribution License (http://creativecommons.org/licenses/by/4.0), which permits unrestricted use, distribution, and reproduction in any medium, provided the original work is properly cited. 